\title{
Estudio fenomenológico sobre las disposiciones docentes en la relación pedagógica
}

Phenomenological Study on the Teaching Dispositionsin the Pedagogical Relation

Artículo de investigación | Research article

Fecha de recepción: 08 de octubre de 2018 Fecha de aceptación: 03 de septiembre de 2019 Fecha de disponibilidad en línea: mayo de 2021

doi: 10.11144/Javeriana.m14.efdd

Diego Martín-Alonso diegomartin@uma.es UniversidAd de Málaga, EsPaña (D) ORCID: https://orcid.org/0000-0001-7367-7862

Nieves Blanco-García nblanco@uma.es

Universidad de Málaga, España ORCID: https://orcid.org/0000-0001-7735-4593

J. Eduardo Sierra-Nieto esierra@uma.es

UnIVERSIDAd de Málaga, EsPaña iD ORCID: https://orcid.org/0000-0002-9925-1656

Para citar este artículo | To cite this article Martín-Alonso, D., Blanco-García, N. \& Sierra-Nieto, J. E. (2021). Estudio fenomenológico sobre las disposiciones docentes en la relación pedagógica. magis, Revista Internacional de Investigación en Educación, 14, 1-23. doi: 10.11144/Javeriana.m14.efdd 


\title{
Resumen
}

Partiendo del marco de la fenomenología vanmaniana, el propósito de este trabajo es profundizar y tratar de captar la esencia de las disposiciones docentes puestas en juego en la construcción de la relación pedagógica. En consecuencia, abordamos el estudio desde un enfoque fenomenológico. A través de relatos anecdóticos vividos con una maestra de educación primaria realizamos un análisis exegético en torno a los tres temas que, en línea con trabajos previos, hemos encontrado: cuidado, responsabilidad y esperanza. Las conclusiones apuntan a estos tres focos como las disposiciones que sustentan el gesto que inicia la relación pedagógica.

\section{Palabras clave}

Actitud del docente; comprensión; investigación pedagógica; relación profesor-alumno; responsabilidad

\begin{abstract}
From the framework of the Van Manen phenomenology, the purpose of this work is to go deep inside and try to capture the essence of the teaching dispositions put into play in the construction of the pedagogical relations. Consequently, we approach the study from a phenomenological perspective. Through a collection of anecdotes lived by a primary school teacher, we carried out an exegetical analysis revolving around three topics which, aligned with previous works, were found as: care, responsibility and hope. The conclusions aim at these three focuses as the dispositions which sustain the gesture which initiates the pedagogical relation.
\end{abstract}

\section{Keywords}

Teacher attitudes; comprehension; educational research; student teacher relationship; responsibility 


\section{Descripción del artículo | Article description}

Artículo de investigación derivado del proyecto Relaciones educativas y creación del currículum: entre la experiencia escolar y la formación inicial del profesorado. Indagaciones narrativas, en el cual, desde un enfoque fenomenológico y a través del trabajo de campo realizado junto a una maestra de educación primaria, los autores reflexionan sobre la naturaleza de la relación pedagógica y las disposiciones docentes que la hacen posible.

\section{Introducción}

de campo, 9 de noviembre de 2017).

¿Qué hacer cuando una niña llora? ¿Cómo actuar ante la desolación de una alumna? No existen reglas para la relación educativa: la esencia de la experiencia relatada no está en una cuestión técnica, la maestra no recurrió a ningún modelo. Tampoco es un acto físico, el cogerle de la muñeca o sentarse juntas, por sí mismo, no constituye esa experiencia. Ni podemos pensar que se trate únicamente de las palabras que le dijo. Sin embargo, se ha producido un encuentro en el que la niña, nos atrevemos a imaginar, ha podido sentirse comprendida, es decir, con el acompañamiento que necesitaba para poder afrontar la situación que estaba viviendo.

En este texto, entendemos que la relación educativa es un encuentro en el que es necesaria la comprensión pedagógica (Van Manen, 1998), una disposición de escucha y aceptación (Sierra \& Blanco, 2017) que permite al docente acercarse a la experiencia del niño(a), percibir su singularidad, así como la historia que se cuenta de sus vivencias (dentro y fuera de la 
escuela), y a través de la cual da sentido a su experiencia (Clandinin \& Connelly, 1998; Huber, Murphy \& Clandinin, 2011).

Aunque la relación educativa se construye desde esta colocación, es importante aclarar que eso no es contrario a que determinados conocimientos metodológicos puedan ayudar a orientar la práctica docente. Pero siempre teniendo en cuenta que la esencia de la relación no está en las competencias técnicas. Entonces, si no se trata de una cuestión técnica ni metodológica, ¿qué disposiciones y saberes docentes sostienen la relación pedagógica?

Esta cuestión ha sido abordada desde estudios fenomenológicos (Ayala, 2011; 2018; Jordán, 2011; Van Manen, 1998), que han apuntado a tres lugares comunes: cuidado, esperanza y responsabilidad. Por ello, partiendo de las inquietudes planteadas, el propósito de este texto es continuar y contribuir a la discusión ya iniciada, profundizando y tratando de captar la esencia de las disposiciones puestas en juego por el profesorado en la construcción de la relación pedagógica. Para ello, y siguiendo la propuesta de Van Manen (2003; 2015), pondremos en diálogo, a través de un análisis temático y exegético, escenas que hemos vivido junto a una maestra ${ }^{1}$ con otros textos centrados en la experiencia vivida y la relación educativa.

\section{Marco teórico}

La tradición curricular entiende la enseñanza como una labor técnica, es decir, en términos de una implementación de los programas de estudio (Aoki, 2012). Como viene siendo analizado desde hace décadas (Gimeno, 1988; Stenhouse, 1987), esta visión de la enseñanza es impersonal y no tiene en cuenta a las personas inmersas en el proceso educativo, tomándolas como sujetos sustituibles e intercambiables. Es decir, lo único importante es, desde este paradigma, la consecución de unos resultados prescritos y observables. Así, la relación educativa se convierte en algo instrumental, el medio para la consecución de unos objetivos, sin importar quién sea el docente ni el alumno.

Sin embargo, apelando tanto a la propia experiencia como a diversos estudios (Contreras, 2010; Piussi \& Mañeru, 2006; Van Manen, 2015), se pone en entredicho la afirmación anterior. La huella que cada docente deja en el alumnado es única, insustituible y, además, no se puede observar plenamente, ni se puede esperar, por tanto, un listado detallado de resultados

1 Este trabajo forma parte de un proyecto de investigación más amplio (Ref: EDU2016-77576-P), en el que hemos acompañado semanalmente a una maestra en su escuela regularmente durante el curso 2017/18. 
que se alcanzan con cada relación. Por lo que la educación no puede reducirse a una aplicación técnica de planes curriculares (Huber et al., 2011; Stenhouse, 1987).

Para abordar estas cuestiones, en este texto nos apoyamos en trabajos fenomenológicos (Ayala, 2018) y de la pedagogía de la diferencia sexual (Blanco, 2011; Piussi \& Mañeru, 2006; Wilson, 2014), que sitúan la relación pedagógica en el centro del proceso educativo. Desde estos trabajos, entendemos la relación educativa como un encuentro (Cima, 2012) entre docente y alumno(a) que media y crea las posibilidades para que pueda producirse un proceso de creación (Montoya, 2004) vinculado a la persona y su historia (Clandinin, 2013). Aquí hablamos de historia en los términos de la tradición de la creación curricular (Huber et al., 2011), que la define como la narración que la persona hace de sus experiencias, de modo que construye un relato a través del cual da sentido a su situación actual y su relación con el mundo.

En línea con esta concepción, desde la fenomenología vanmaniana se entiende que la relación educativa se establece al orientarse "hacia el niño, a la naturaleza inmanente del ser y del llegar a ser" (Van Manen, 1998, p. 47), de modo que el adulto le acoge de manera existencial. Partiendo de ideas similares, Rivera $(2012$, p. 34) explica que la relación educativa es una relación sin fin, "en su doble sentido de relación inacabable e inagotable como fuente de significado de la vida y la convivencia humana, y, también, de relación no instrumental, o sea, de relación que no tiene otro fin que la relación misma". Por tanto, entender la educación como una experiencia de relación supone conocer y aceptar a la otra persona, lo cual exige, en consecuencia, también aceptar la incertidumbre de la alteridad (Contreras, 2002).

En consecuencia, la relación requiere preocuparse por las circunstancias, siempre singulares, de cada niño y cada niña. Esto es lo que podemos denominar como comprensión pedagógica, "la capacidad de apreciar y escuchar a los niños" (Van Manen, 1998, p. 98), que implica conocer al otro e interesarse por lo que es mejor para él o ella. La comprensión pedagógica requiere de la escucha (Sierra \& Blanco, 2017) y la aceptación de la historia del otro para poder conocerle, estar disponible y acompañarle en su proceso (Martín-Alonso, Blanco \& Sierra, 2019). En otras palabras, es la capacidad de ser sensible a la vida interior del niño y a su singularidad en un contexto de pluralidad (Rivera, 2012).

Por tanto, en la construcción de la relación pedagógica, el docente trata de acercarse a la singularidad de cada criatura y, por ello, cada relación será también singular e imprevisible. En consecuencia, nos señalan Molina, Blanco \& Arbiol (2016), la relación educativa es un asunto complicado que no se puede reducir a un conjunto de reglas o habilidades. 
Entonces ¿qué disposiciones docentes sostienen la relación pedagógica?, ¿qué saberes se ponen en juego en su construcción?, Van Manen (1998), cuya obra será el punto de partida de este artículo, señala tres "condiciones" necesarias para la acción pedagógica: amor, responsabilidad y esperanza pedagógica.

El amor pedagógico alude a la aceptación de lo que hace único y singular a cada niño(a). Algo que Jordán (2011, p. 63) expresa a través de la idea: "Te quiero como eres, pero también como lo que aún no eres y estás llamado a ser". Desde otros trabajos se nombra, en una línea similar, a este amor pedagógico como cuidado, que supone un encuentro entre dos personas (un cuidador y un cuidado²), que surge cuando el cuidador se preocupa y responsabiliza por el bienestar y desarrollo de la otra persona, que debe reconocerse como cuidado para completar la relación (Goldstein, 1998).

La responsabilidad pedagógica remite no a una tarea, en términos de obligaciones futuras o de la rendición de cuentas por acciones pasadas, sino a una virtud y un modo de actuar en presencia del otro (Van Manen, 2015). Así, la responsabilidad solo es posible cuando se actúa libremente y de manera reflexiva, ya que de lo contrario no se puede asumir la responsabilidad de las propias acciones. En definitiva, es una inclinación pedagógica, un "sentirse reclamado" por el niño o la niña, que mueve a escuchar su vida interior, cuidarle y ayudarle en su crecimiento (Ayala, 2018).

La esperanza pedagógica se entiende como la confianza en el otro y en quien puede llegar a ser (Ayala, 2011). Más que un modo de actuar, la esperanza evoca a una forma de estar en relación que se sostiene en la confianza. Esto se vincula con la creación de espacios donde poder apasionarse, cuestionarse y recrearse (Molina et al., 2016), confiando en que, de esta manera, se nutra la posibilidad de ser, de que algo suceda en el alumno. En palabras de Van Manen (1998, p. 81), "la esperanza se nutre de la paciencia, la apertura, la creencia y la confianza en las posibilidades de nuestros menores. Cuando ellos perciben nuestra confianza se ven animados a confiar en sí mismos. La confianza les hace capaces".

Por último, es importante aclarar que esto no supone dejar de lado el conocimiento pedagógico disciplinar, sino entenderlo como un "saber constituyente de la experiencia" (Contreras, 2010). Es decir, como saberes que no dan respuesta a la particularidad y novedad de la experiencia, pero sí pueden servir para orientar las decisiones y convertir en fructíferas las tensiones inherentes a la práctica pedagógica (Contreras, 2016).

2 Traducción propia de los términos ingleses one-caring y cared-for (Goldstein, 1998; Noddings, 2005) como 'cuidador' y 'cuidado', respectivamente. 


\section{Metodología}

\section{Enfoque fenomenológico}

El interés por ahondar en la naturaleza de la relación pedagógica y las disposiciones docentes que la hacen posible nos lleva a abordar el trabajo desde un enfoque fenomenológico (Van Manen, 2015). Entendemos que la fenomenología se ocupa de lo que se vive y lo que podemos pensar a partir de ello, manteniéndose siempre apegada al acontecimiento. Es decir, busca partir de las descripciones anecdóticas (Ayala, 2018) para iniciar un proceso de reflexión sobre la esencia de la experiencia narrada.

El término "esencia" deriva del verbo "ser", que, por definición, es una noción profundamente existencial. Pregunta lo que algo "es" para aquel que formula la pregunta. La esencia interroga sobre lo que algo "es" y sin lo cual no podría ser lo que es (Van Manen, 2003, p. 14).

La fenomenología se centra, por tanto, en formular preguntas ontológicas, buscando una orientación que permita que la esencia de la enseñanza nos hable. De este modo, ponemos el foco, en este texto, en una cuestión central en los estudios fenomenológicos clásicos: la esencia de la pedagogía y la relación pedagógica. Es decir, ¿qué constituye la esencia estructural de la relación pedagógica?

La imprevisibilidad y singularidad del encuentro educativo hace que no sea reducible a una técnica, método o teoría. Además, al pasar la experiencia a texto siempre se pierde algo, por lo que no podemos intentar describirla completamente, aunque sí orientarnos hacia ella. Este carácter inefable e imprevisible de la experiencia hace que, en este estudio, partamos de relatos anecdóticos que nos orientan hacia la naturaleza de la relación pedagógica, en lugar de pretender describirla (Aoki, 2012).

Entendemos la anécdota como un instrumento metodológico (Van Manen, 2003) que consiste en la narración de una vivencia que ayuda a hacer visible la naturaleza del fenómeno de estudio y, por tanto, permite aprehender la esencia de la experiencia, apegándonos a la vivencia sin interpretarla o teorizarla. En definitiva, se trata de un intento por acceder al mundo experiencial donde se asientan las disposiciones de maestros y maestras en la construcción de la relación educativa.

\section{Proceso de la investigación}

Para abordar las preguntas de investigación hemos entrado en relación con Clara, una maestra de educación primaria. La hemos acompañado semanalmente durante el curso 2017/18 en su escuela, situada en una zona 
empobrecida de la ciudad de Málaga, España, en la que ocupa el cargo de jefa de estudios y, además, trabaja como maestra de apoyo. Clara, titulada en Magisterio y Psicología, tiene una extensa experiencia docente, ya que ha trabajado como maestra en varios centros durante más de veinte años.

Decidimos iniciar la investigación con ella porque en su labor docente se muestra sensible a la vida e historia de los niños y las niñas, con una actitud reflexiva y comprensiva en el cuidado de la relación con ellos. Algo que se traduce en su práctica diaria, como hemos podido conocer, en una disposición de apertura, acogida y disponibilidad.

De este modo, en este texto partimos de descripciones de experiencia vivida (Ayala, 2011) recogidas durante el estudio con Clara. El propósito no es determinar si su práctica es o no adecuada, sino que su experiencia nos sirva para pensar, desde situaciones concretas, en las condiciones que construyen la relación pedagógica.

El proceso de recogida de material experiencial se ha realizado mediante la observación de cerca (Van Manen, 2003) y conversaciones hermenéuticas (Sierra \& Blanco, 2017), realizando un total de 18 registros observacionales y 10 conversaciones que han permitido la construcción de relatos anecdóticos ${ }^{3}$. Finalmente, se han analizado otras fuentes de materiales anecdóticos con los que poder abordar el análisis posterior.

\section{Destapar aspectos temáticos de la relación pedagógica}

El carácter inefable de la experiencia hace que no podamos describirla o captarla plenamente, pero sí apuntar a estructuras de significado del fenómeno. Por tanto, siguiendo el enfoque fenomenológico-hermenéutico, no pretendemos formular conclusiones cerradas, ya que esta no parece la mejor manera de acercarse a la experiencia vivida. Así, el propósito final de este trabajo es la construcción de un texto evocativo que permita destapar aspectos temáticos de la experiencia, es decir, las disposiciones que hacen que la relación pedagógica sea tal (Aoki, 2012; Van Manen, 2015).

Para ello, una vez recogidas las descripciones de experiencia vivida realizamos un análisis temático, es decir, buscamos las estructuras experienciales que componen las vivencias relatadas tratando de extraer significado de ellas: "Un tema es la forma de captar el fenómeno que uno intenta entender. El tema describe un aspecto de la estructura de la experiencia vivida" (Van Manen, 2003, p. 105). En este proceso recurrimos también al aislamiento de afirmaciones temáticas (Ayala, 2011).

3 En este texto incluimos una selección de relatos que nos permitirán guiar la reflexión, aunque el proceso de análisis se realizó con un registro más amplio. 
En consecuencia, la fase final del análisis y escritura del texto se hizo en forma temática, es decir, el texto se dividió en los tres temas que surgieron y que coinciden con estudios fenomenológicos previos: cuidado, responsabilidad y esperanza (Jordán, 2011). Finalmente, cada tema se aborda a través de material anecdótico que se pone en discusión con estudios previos sobre la relación educativa.

La tradición fenomenológica propone hacer este análisis, exegético, a través de la conversación con otros textos fenomenológicos. Sin embargo, en este trabajo, además, utilizaremos estudios de la pedagogía de la diferencia sexual, ya que estos han abordado, también apegados a la experiencia vivida, los temas que aparecieron y nos guiaron en el análisis final.

\section{Resultados y discusión}

\section{Cuidado}

Estamos en la clase de primero, son niños de cinco y seis años. Clara les ha propuesto, con algunas directrices, que de forma individual pinten, dibujen y coloreen. Mientras van haciendo cada uno la tarea, la maestra va llamando a los niños de uno en uno para que lean un texto con ella. De este modo, cada uno va trabajando a su ritmo.

Clara está leyendo con una alumna. Cada niño está inmerso en su tarea. El ambiente en clase es de serenidad y concentración. De repente se escucha un llanto.

—¿Quién llora? — pregunta Clara.

Echa un vistazo y descubre a Sergio desconsolado. La maestra se acerca a su sitio. El chico esta tumbado sobre su mesa y llora angustiado. No habla, solo llora. Está rodeado por un grupo de compañeros que se acaban de levantar, algunos preocupados y otros interesados en saber qué está pasando. Clara coge un pañuelo, se lo da, le coge de la mano y le lleva a su mesa. Le sienta, le seca las lágrimas con el pañuelo que acaba de coger y le limpia los mocos.

—¿Qué ha pasado?

Sergio no contesta, sigue llorando. Le falta el aire a causa del llanto; aunque quisiese, tampoco podría hablar.

— ¿No te gusta el dibujo? —insiste Clara.

—No — consigue decir Sergio entre lágrimas. 
— ¿Pero lo has hecho tú?

—Sí —el llanto se va ralentizando.

— ¿Y no te ha gustado?

—No —aunque más calmado, las lágrimas siguen cayendo por sus mejillas.

- Bueno eso se puede arreglar, luego lo arreglamos - Sergio mira a la maestra, no parece convencido de lo que está escuchando-. Vamos a leer y luego lo arreglamos.

La maestra abre la libreta y empieza a leer. El niño se sitúa frente al texto, se calma casi instantáneamente y continúa la lectura. Su agobio parece haber desaparecido.

Cuando han terminado, Sergio se levanta, pero, antes de que se gire en dirección a su mesa, Clara le dice:

—Cuando te equivoques, piensa cómo se puede arreglar.

Sergio sonríe y baja la mirada.

— ¿Llorar te ha servido? — pregunta Clara.

-Es que he puesto otro color.

— ¿Y no se puede arreglar?

- Sí.

— ¿Llorando se arregla?

-No.

—Piensa, busca la solución.

Sergio va a su mesa y sigue trabajando en el mismo dibujo que tanto le frustró hace diez minutos. Continúa inmerso en su obra durante el resto de la clase (Cuaderno de campo, 28 de noviembre de 2017).

¿Por qué ha dejado de llorar Sergio y ha vuelto a su dibujo? ¿Qué hay detrás del llanto que llama a la maestra a iniciar su acción? Sergio "ha puesto otro color" y la incertidumbre ante la situación que se le presentaba ha desembocado en un Ilanto desconsolado. Manifestaba así la necesidad de apoyo, de alguien que le ayudase a abordar la situación y a encontrar 
una solución, aunque es difícil saber si este llanto es una llamada consciente o solo el resultado de un sentir desalentador. En cualquier caso, la maestra se siente reclamada ("iquién llora?", dice) y acude en busca del niño que le necesita. Así, esta escena se origina cuando la maestra acude al lugar, físico y simbólico, de Sergio para ayudarle a abordar su necesidad.

A partir de esta anécdota, podemos pensar que la relación educativa comienza cuando una persona requiere de algo concreto para crecer, es decir, cuando tiene una necesidad. La maestra escucha al niño, su necesidad y le ayuda a afrontarla. Lo que está en juego es algo más que un conflicto circunstancial y temporal, es el crecimiento del niño. No se trata, entonces, de satisfacer un deseo momentáneo, sino de buscar lo que realmente demanda su proceso madurativo (Noddings, 2005). En palabras de Bustamante-Zamudio (2012, p. 170), es el cuidado lo que permite a la persona "sobrevivir para ingresar a lo humano, toda vez que, dejado a su propio 'desarrollo', es poco probable que sobreviva".

Esta necesidad no tiene que ser reclamada siempre de forma explícita o como un llanto ni tiene que ser una situación urgente: se trata de atender lo que el otro necesita para crecer. En este caso, Sergio necesitaba sosegarse, limpiarse los mocos y construir recursos para abordar la situación. Pero esto es algo que va más allá del dibujo y la necesidad urgente que tenía Sergio de corregirlo: podemos pensar esta experiencia de cuidado no como una satisfacción de la necesidad de una solución al dibujo, sino como una mediación para construir los recursos necesarios para poder abordar futuras experiencias de desacierto o equivocación.

En este sentido, resuenan las palabras de la maestra, que no apuntan solo al momento presente, sino al crecimiento del niño: "Cuando te equivoques, piensa cómo se puede arreglar". De este modo, Sergio a través del ejercicio de lectura y la conversación con la maestra encuentra la distancia adecuada para abordar con sosiego el conflicto que se le planteaba y, esto es lo principal, posibles futuras situaciones.

Así, la relación se convierte en educativa cuando se orienta al cuidado del otro y a sus necesidades. El cuidado consiste en la creación de un espacio de posibilidad de ser, de seguridad, en el que re-crear la propia historia con el acompañamiento del educador (Piussi \& Mañeru, 2006). Por tanto, el cuidado no es tanto una forma de ser, sino una manera de entrar en relación, un actuar orientado al bien del otro, preocupándose por él y por lo que necesita (Goldstein, 1998).

El educador se proyecta hacia el futuro de la persona cuidada y sus necesidades, no hacia un estar placentero, agradable y que cubra deseos temporales, como sucede con Sergio. En el momento en que se está en relación, el cuidado puede frustrar, hacer llorar, aliviar un sufrimiento, doler o 
generar placer. Sin embargo, posteriormente, toda experiencia de cuidado se dirige al mismo lugar: el crecimiento de la persona, que no podrá volver a contar su historia de la misma manera.

Clara ha explicado qué son las palabras primitivas y derivadas y, después, el grupo se ha puesto a trabajar, haciendo ejercicios sobre el tema. Clara va de mesa en mesa viendo cómo están trabajando y ayudando a los que lo necesitan. En este deambular se da cuenta de que la mayoría de la clase no ha entendido una de las actividades, así que se mueve hasta la pizarra, en el centro de la clase, para dirigirse al grupo:

—Parece que el segundo ejercicio no os sale. Blanca, ¿qué has puesto tú?

— ¿Pero, seño, y si me equivoco? — pregunta la alumna con miedo.

—Pues te equivocas — responde con desapego y tranquilidad.

—Pero... ¿y si está mal? —insiste la alumna.

Parece que el anterior intento no le sirvió para lanzarse a participar y Clara le ofrece una solución:

— ¿Y si yo te digo las palabras y tú vas diciendo si son o no derivadas de la palabra cabello?

—Vale — dice Blanca con mirada baja y voz alicaída.

— ¿Pintura? — pregunta la maestra.

- No.

- ¿Ángel?

-No.

- ¿Cabellera?

- Sí.

En ese momento, a pesar de no haberse equivocado, Blanca empieza a llorar. Baja la cabeza, la apoya contra la mesa y se tapa la cara con los brazos. Clara lo ignora y continúa con el ejercicio preguntándole a otro alumno.

Cuando terminan, parece que todos lo han entendido. Entonces Blanca deja de llorar y levanta la cabeza de la mesa. En ese momento Clara va hacia el lugar de Blanca y, apoyando la mano en su hombro, le dice: 
- Tienes que aprender a equivocarte, esa es la manera de aprender y mejorar.

Poco tiempo después termina la clase. Al salir, Clara me explica que ve llorar a chicos y chicas en esta clase con relativa frecuencia:

- Yo sé por qué lloran, porque les pongo en la tesitura de explicar, y no están acostumbrados. Todo el rato les digo: "¿Por qué?", "Dímelo", "Explícamelo". [...] Ayer estuve corrigiendo y les dije: "Venga, id saliendo y vais explicando, intentad salir sin libreta". Se deshacen. No tienen seguridad porque están acostumbrados a salir, copiar de la libreta e irse. O decir el resultado sin todo lo que hay por medio.

-Desde aquella semana están estupendas, necesitaban ese clic, necesitaban que alguien les tirase. Ahora, cuando vengo a esta clase, las que más lloraban son las primeras que vienen a abrazarme (Cuaderno de campo, 14 de noviembre de 2017).

¿No se actúa siempre de la misma manera cuando una criatura llora? ¿Por qué deja la maestra llorar a Blanca mientras que a Sergio le atiende inmediatamente? Esta escena nos señala a un lugar esencial de la relación educativa: no debemos confundir el cuidado con un trato cariñoso o cálido, ya que esta es una simplificación que pone límites a la labor docente. El cuidado pedagógico no siempre es grato, ya que no siempre tienen que coincidir las necesidades con deseos circunstanciales o eventuales, puesto que nadie quiere vivir una experiencia desagradable. En palabras de Biesta (2017, p. 76), los docentes deben provocar también las "verdades incómodas", de modo que trabajen "activa y coherentemente en la distinción entre lo que es deseado y lo que es deseable para explorar qué es lo que debe tener autoridad en nuestras vidas". Por ejemplo, en este caso, la niña reclamaba aprobación y, en cambio, Clara pensaba que lo que necesitaba era exponerse, pensar y tratar de justificar su ejercicio, aunque fuese una situación lacerante o que le pudiese hacer llorar.

El cuidado responde, en consecuencia, a un contexto particular, enraizado en la singularidad de las dos personas que entran en relación. Esto coloca al educador en una situación difícil: algunas de las manifestaciones del alumnado pueden ser deseos pasajeros y otras necesidades reales que deben ser consideradas, ¿cómo saber cuáles atender y cómo actuar?

En esta tensión continua entre deseos y necesidades, el docente precisa moverse con una disposición de apertura y receptividad que le lleve a comprender la vida interior del otro (Van Manen, 1998). Así, el educador 
podrá tener en cuenta en su práctica los deseos, anhelos y objetivos que ha percibido al tratar de acercarse a la otra persona. Podemos decir, por tanto, que la disposición al cuidado exige y mueve a mantener una disposición de apertura, escucha y aceptación de lo que el otro trae y necesita para poder atender a sus necesidades. El cuidado significa prestar atención a la historia de la criatura para entrar en relación con ella y que este encuentro medie en su recreación.

Como nos recuerda López (2006, p. 136), "la mediación educativa surge de [esta] necesidad que toda criatura humana siente de entrar en relación con otra o con otro para construir su propio ser y su propia relación con el mundo". Así, el movimiento de acercamiento al otro se hace desde el propio ser de la maestra, que se pone en juego en primera persona, de modo que la relación pedagógica (que es de disparidad) no deja a ninguno indiferente, ya que ninguno podrá volver a contarse su historia de la misma manera. De este modo, el encuentro con el otro termina convirtiéndose en un encuentro con uno mismo (tanto cuidador, como cuidado).

Es precisamente esto lo que podemos observar en Blanca: el encuentro con la maestra le hace ponerse en juego, con su dificultad para explicar la actividad y su miedo a exponerse y equivocarse, una situación que termina con el llanto. Por tanto, el cuidado va más allá de la observación y atención a las demandas del otro, e impele a una dimensión existencial, a la esencia del ser de las dos personas inmersas en la relación.

\section{Responsabilidad}

-Go-mi-no-la.

—Ahora lee todo junto — dice Clara.

Elena, de seis años, vuelve a leer marcando, nuevamente, cada sílaba. De repente, por su rostro caen dos lágrimas. Clara lo ignora y lee a modo de ejemplo, para que la niña escuche la entonación y le pide que pruebe ella a hacer lo mismo. Elena no responde.

—Ven aquí — dice Clara con delicadeza.

Elena va hasta el lugar de la maestra, con la cabeza agachada.

—Sabes leerlo todo junto porque te he visto hacerlo otros días; ¿qué te pasa?, ¿me das una sonrisa?

Elena se queda inmóvil. No reacciona. Parece que no hubiese escuchado nada. 
—Bueno, yo te voy a sacar una sonrisa — dice Clara, a la vez que juega a hacerle cosquillas.

Pero su intento fracasa, la niña permanece impasible. Parece que solo estuviese esperando a que termine para volver a su sitio. Clara hace un intento nuevo de conectar con la chica:

— ¿Qué pasa? ¿Estás enfadada? iVenga, pégame! —dice mientras le pone las manos cerca para que pueda golpearlas sin hacerse daño.

Elena comienza esquivando las manos de la maestra y el movimiento pasa a transformarse en pequeños gestos de rabia y golpes en el brazo de Clara. Continúa pegando, cada vez más fuerte, hasta que se descontrola y, en ese momento, Clara la detiene con un largo abrazo que la niña le devuelve entre lágrimas. Finalmente vuelve a su sitio y permanece allí, con la mirada perdida, el resto de la clase.

Clara no ha logrado que la niña avance con la tarea de lectura, ni tampoco parece haber conseguido conectar con lo que estaba viviendo por dentro, algo que después me confirma:

— ¿Te has fijado en la actitud en clase? Está caída en la silla, todo el día diciendo: "Ay, seño, no quiero". Yo algo tengo que hacer. Estoy dándole vueltas, he probado con todo (Cuaderno de campo, 14 de marzo de 2018).

Aunque no se produzca un encuentro con la niña y ella no pueda reconocer el cuidado de la maestra, la escena nos permite pensar que hay un juego al acercarse al otro para cuidarle: una escucha constante de su historia y lo que necesita. ¿Qué está demandando Elena? ¿Qué está viviendo que la mantiene impasible? Estas son las preguntas que podemos entrever con los vaivenes de Clara, que en su intento por conectar con lo que está sintiendo la niña pasa de la ignorancia, al jugueteo y a la provocación.

La cuestión que surge, entonces, es: ¿qué mueve a una persona a preocuparse por comprender las necesidades y el cuidado del otro? Tal como hemos visto con el movimiento de Clara al atender a Sergio y a Blanca, podemos pensar que el cuidado se sostiene en algo más que un sentimiento. Se trata de una acción que surge de una posición moral (Goldstein, 1998), que entiende al otro como una persona a la que cuidar, haciéndole así asumir la responsabilidad de escucharle y comprender qué necesita. Esta es la disposición que muestra Clara en la escena con Elena, una búsqueda continua de la necesidad de la niña. Es un intento que, al quedarse abierto, nos permite ver con mayor claridad la responsabilidad que asume la maestra y a la que no renuncia: "Algo tengo que hacer". 
¿De dónde surge esta responsabilidad? Para pensar en ello podemos recurrir al origen etimológico de la palabra: responsare, del latín, que significa 'responder'. Esto es precisamente lo que intenta repetida y erradamente la maestra: dar respuesta a las necesidades de Elena. Dice Van Manen (1998) que la necesidad de los niños y las niñas se siente como una llamada, una voz, que el educador escucha y que le mueve a buscar la mejor respuesta, es decir, a cuidarle. Por ejemplo, esta es la llamada, explícita, de Sergio cuando comienza a llorar y que es acogida por Clara: "¿Quién llora?", pregunta al oír el Ilanto, y acude súbitamente en su búsqueda. Es precisamente la escucha a esta llamada y el compromiso de responderla lo que Zambrano (2007, p. 106) Ilama la "vocación de maestro":

[La vocación] es una llamada oída y seguida. Vocare viene de la raíz vox, vocis, la voz. La vocación, pues, no es la misma voz sino algo que resulta de ella; es algo que ha sucedido a consecuencia de esa voz y que adquiere entidad. La adquiere, claro está, en quien la acoge y no solamente la oye.

\section{Esperanza}

Clara estaba explicando a un grupo de alumnas que se iban a plantar semillas de zanahorias en el huerto del colegio. Para ello le fue encargando una tarea a cada una y, al dirigirse a Maite, le dijo:

—Antes de poner las semillas, tenemos que echar un poco de agua en cada hilera, pero no mucho, ¿cómo lo hacemos?

La niña buscó un cubo, lo llenó de agua y se encontró con que pesaba demasiado y no podía levantarlo con facilidad:

— ¿Cómo lo hago, seño? Yo no puedo hacerlo.

—Sí que puedes, busca la manera — dice la maestra instantáneamente.

-No puedo.

—Sí que puedes —insiste Clara.

Al ver que no encontraría la solución en la maestra, Maite comenzó a probar diversas formas de regar la zona. Comenzó tratando de verter el agua con cuidado, pero el peso hizo que se le cayera toda el agua. Después pidió ayuda a un compañero, con idéntico resultado. Finalmente, descubrió que podía echar poca cantidad de agua en el cubo, regar, y volver a la fuente para empezar el proceso, de modo que podía transportarlo y manejarlo sin esfuerzo (Cuaderno de campo, 27 de octubre de 2017). 
En el cuidado a la alumna, Clara interpreta que su necesidad en ese momento es la de perderse, pensar, equivocarse y buscar la solución al dilema que se le presentaba, algo que no habría hecho sin confiar en que sería capaz. Podemos pensar así que la necesidad va unida a la esperanza, porque no es otra cosa que necesidad de ser y que se proyecta en la persona que aún no ha sido, pero puede llegar a ser. Siguiendo con Zambrano (2007, p. 124): "Por lo que el hombre tiene de no ser, de ser 'in via', en tránsito, está movido por la esperanza. Mas, por lo que tiene de real, por lo que ya es: alma, cuerpo, está sujeto a la necesidad".

Lo que esta anécdota nos da a pensar es cómo el cuidado está impregnado por la esperanza por lo que el otro puede llegar a ser. Cuando se atiende una necesidad se hace en nombre de la esperanza, pues siempre que se acude al encuentro con el otro se hace aguardando su crecimiento. De lo contrario, sin confianza, la necesidad puede llegar a abatirnos.

¿Habría iniciado Clara el proyecto del huerto si no hubiese confiado en los chicos y las chicas? ¿Habría propuesto la tarea a Maite si no la hubiese creído capaz de hacerlo? Es la esperanza en la niña la que le hace asumir la responsabilidad de crear el espacio para que recuente su historia y pase del "yo no puedo hacerlo" a culminar la tarea con éxito. Podemos pensar, también, en la escena de Sergio, en la que la confianza de Clara en que podría abordar el conflicto con su dibujo ("Piensa, busca la solución", le decía) le permitió resolver su conflicto y continuar el trabajo.

— ¿Por qué tienes eso tachado? — pregunta Clara al ver la libreta de Sara.

—Porque me lo dijo Laura — responde la niña.

— ¿Y por qué le haces caso?

—Porque Laura es más lista que yo — dice la niña con desazón.

— ¿Y eso por qué?

—Porque lo dice todo el mundo.

—Todo el mundo no, yo no lo digo. ¿Por qué dices que Laura es más inteligente que tú? —vuelve a insistir la maestra de modo tajante.

-Porque saca mejores notas, ella nunca ha sacado un cinco, y yo he sacado un cuatro algunas veces.

-Solo por eso no puede ser más lista. Puede ser que haga las tareas o que estudie en casa y atienda más en clase, por eso saca mejores notas. Pero 
eso no es que sea más lista, sino que es más trabajadora. Pero tú no digas que no eres lista, porque tú eres muy lista.

— ¿Ah, sí? ¿En qué? — pregunta Sara con curiosidad (Cuaderno de campo, 14 de marzo de 2018).

La esperanza no es confianza ciega en los otros, en plural; es esperanza en el otro, que es singular y cuyas posibilidades de ser son únicas. Esto exige conocer a la persona, acercarse a su singularidad y relacionarse desde ahí con ella. "¿Ah, sí? ¿En qué?", pregunta con expectación Sara, algo que podemos interpretar como "¿En qué soy yo lista? ¿Qué podría yo llegar a ser y que aún no soy?".

De este modo, la esperanza despierta en la niña la conciencia de algo que podría llegar a ser y que no sabía, le permite percibir algo que no veía antes en sí misma, generando curiosidad e inquietud por saberse y conocerse más allá de lo que es en ese momento, y que termina expresándose con las preguntas "¿Ah, sí? ¿En qué?".

Entonces, creer en el otro, además de mover a la maestra a cuidarle, crea el espacio para que el alumnado confíe en sí mismo, en sus propias capacidades y se mueva a desarrollarlas. La esperanza de la maestra le da a los chicos y chicas una imagen nueva de sí mismos, una manera diferente en la que mirarse y poder sentirse con capacidad de crecer. Es esto lo que podrá impulsar a Sara, por ejemplo, a abordar problemas y obstáculos, al creerse capaz de hacerlo por sí misma y sin necesidad de "tachar" su propio trabajo (¿o tacharse a sí misma?). Algo similar sucede con la experiencia de Maite en el huerto: es la esperanza de la maestra en que la niña encontraría la manera de resolver el problema la que gesta el espacio para que ella misma termine viéndose capaz de hacerlo.

Si Sara tenía bien hecha la tarea, ¿por qué se fijó Clara en la parte que tenía tachada? La misma pregunta surge si recordamos la anécdota con Blanca, la niña había hecho bien el ejercicio, pero la maestra miraba a otro lugar. ¿Dónde? En estas escenas la maestra no se ciñe solo a los resultados obtenidos (que se podrían vincular a los objetivos establecidos en los programas curriculares), sino a la relación con cada alumna y lo que percibe, a partir de esa relación, que necesitan.

Por el contrario, cuando la esperanza se pierde, nos señala Montoya (2006), se traslada la confianza a los contenidos preestablecidos en los planes curriculares, que pasan a ser el centro del proceso educativo. Y así, en lugar de ser una "relación sin fin" (Rivera, 2012), se convierte en una relación instrumental para el logro de unos objetivos prescritos, que son el resultado de las necesidades inferidas por los agentes encargados de diseñar 
los programas curriculares, y que, obviamente, no conocen a Blanca ni a Sara. De este modo, ante el desconocimiento de las niñas, los programas curriculares no pueden acoger su singularidad y su posibilidad de ser.

Podríamos decir, por tanto, que es importante no confundir la esperanza, el esperar que algo suceda, con que suceda algo esperado. La esperanza supone confiar en la posibilidad de ser, de que la persona crezca, sin que esto signifique llegar a ser como el educador quiere o como espera el plan curricular. Dicho de otro modo, cada uno debe vivir y recrear su propio currículum.

Yo conozco a María y veo que es una niña inteligente. Que esa manera de destacar es porque ella se da cuenta que no sabe y no quiere que lo vea ninguna de sus amigas, la única manera que tiene de defenderse es "Yo sé, déjame ya". Pero luego, en cuanto tú hablas con ella, ya tranquila y le explicas, se hunde, llora y te dice "Es verdad, seño, ya no lo voy a hacer", y lo intenta de verdad. [...] María el año pasado un día me dijo: "No puedo más contigo, tú siempre quieres más, lo consigo y ahora otra cosa más". Eso a mí me gusta, porque significa que le estoy poniendo entre la espada y la pared para que dé un paso más. Entonces yo le digo: "Es que la vida siempre es más" (Cuaderno de campo, 16 de febrero de 2018).

¿Cómo evitar la confusión entre la espera y lo esperado? Tal como le sucede a Clara con María, la relación educativa exige que en todo momento el educador se acerque a la situación actual del joven para, a partir de ahí, pensar cómo avanzar. La interpretación del "Yo sé, déjame ya" de María solo es posible en una relación de apertura y acogida a todo lo que la niña trae. Por tanto, entrar en relación desde la esperanza en el otro se traduce en un movimiento de escucha, percibiendo más allá de sus posibles dificultades o de "lo que le falta", para entrar en contacto con su historia y sus posibilidades.

En la situación contraria, cuando no se escucha al otro, lo tapamos con lo que queremos o esperamos de él, sin dar espacio a su historia, porque no confiamos en que pueda llegar a ser por sí mismo. Entonces, podemos concluir que escuchar supone dar lugar a la historia de cada uno y a la posibilidad de que sea recreada.

Se puede resumir esta disposición, esta búsqueda constante de "otra cosa más", con la expresión con la que concluye Clara: "Es que la vida siempre es más". Como nos decía Zambrano (2007), las personas somos en "tránsito", algo que los educadores debemos tener siempre presente es ¿qué sentido tendría entrar en relación sin creer que el cambio y el desarrollo es posible? 
De este modo, la necesidad de la criatura llama al educador, que acude a su cuidado solo cuando tiene esperanza en que crecerá. Al mismo tiempo, este movimiento llama a la otra persona a ser, movilizándola y reclamándole el cambio, como le sucede a María. Esta demanda le exige salir de una zona de comodidad para entrar en un terreno desconocido, que, por ello, puede abrumar: lo que aún no es ("No puedo más contigo, tú siempre quieres más", refunfuñaba María).

En definitiva, trabajar en el aula desde la esperanza en el otro supone que el educador se desplace al centro del proceso educativo (un lugar tradicionalmente ocupado por los planes curriculares) y se ponga en relación con el alumnado para escuchar, comprender y exigir a cada joven lo que pueda llegar a ser. De este modo, podemos definir la esperanza como la capacidad de maravillarse ante el crecimiento de la otra persona, creer en su posibilidad de cambio y de construir su propia vida (Ayala, 2011).

\section{Conclusión}

Si releemos las escenas relatadas pensando en el cuidado, la responsabilidad y la esperanza observamos un gesto que se repite: los niños y las niñas expresan una necesidad, la maestra escucha su llamada, acude al encuentro y, finalmente, se retira.

Clara comienza buscando al niño que llora, cuando encuentra a Sergio le seca las lágrimas, le calma, le invita a buscar una solución al problema y, por último, le deja marchar para que se enfrente de nuevo a su dibujo. Al conocer el problema de Blanca, la enfrenta a su dificultad y sus miedos pidiéndole que se exponga y defienda su trabajo para que busque maneras distintas de relacionarse con el error ("Tienes que aprender a equivocarte", decía) y, entonces, va a atender al resto de la clase, dejándola con la experiencia de ese encuentro aún removiéndola. A Maite acude para plantearle la tarea del cultivo e instantáneamente la deja sola y no vuelve, a pesar del repetido reclamo de la niña. Por último, y en contraste, con Elena no podemos ver este gesto de retirada porque, precisamente, el cuidado no ha sido fructífero, Clara debe aún acompañar a la niña, buscando qué hacer, antes de poder retirarse.

El propósito del cuidado es que los chicos y chicas crezcan, y la esperanza es que lograrán hacerlo. Es decir, es en la relación pedagógica donde se re-crea la historia de cada criatura y, conforme van haciéndolo, el educador debe ir retirándose, pues ya no le necesita.

Al asumir la responsabilidad por el cuidado de la otra persona y su bienestar, el educador va al lugar de los niños y las niñas para acompañarles en su proceso de maduración. Si en el fondo esperamos que la criatura 
crezca, cuando lo haga debemos retirarnos. De lo contrario, si nos quedamos cuando ya no nos necesita, cuando no nos llama, podemos impedirle la posibilidad de ser por sí mismo.

Por tanto, el gesto de la relación pedagógica es el de asumir la responsabilidad por ir al encuentro, con cuidado y esperanza, para retirarse después. Esto es lo que sucedió con Paula, la niña con la que iniciamos el texto. La maestra se acercó a ella y la acompañó hasta que consiguió aceptar que había perdido parte del desayuno. En ese momento Clara rechazó la galleta que le ofreció la niña, invitándola a finalizar ese encuentro y volver, sola, junto a sus compañeros para seguir jugando.

No es casual que este gesto de retirada sea reiterado, se trata de un proceso simbólico de separación inherente al origen mismo de la vida. La madre, que tiene dentro a su hijo, le alimenta, da oxígeno, le cuida y le da la vida, pero sabiendo que, al final, está destinada a dejarle. Es otra vida, no la suya. Y, cuando crezca y no necesite su cuidado, deberá retirarse y dejarle ser.

En el difícil (y quizá equivocado) intento por concluir un texto fenomenológico, debemos volver a la pregunta con que iniciamos el artículo: ¿qué disposiciones docentes sostienen la relación pedagógica? A partir del análisis y la literatura revisada, podemos decir que las condiciones esenciales (en sentido fenomenológico) para la construcción de la relación pedagógica son el cuidado, la responsabilidad y la esperanza pedagógica. Estas disposiciones se concretan en la práctica docente en un movimiento de acercamiento y retirada, que exige al educador un esfuerzo continuo por comprender a la criatura, su historia y lo que necesita para re-crearla, de modo que pueda acompañarla hasta que sea necesario.

Se trata de escuchar al otro para saber dónde está, atender a su singularidad, y cuidarle con la confianza de que podrá construir su propio camino. Así, comprensión pedagógica significa admirar al otro y apreciarle por lo que es, para acompañarle en su proceso, siempre en tránsito, del llegar a ser.

\section{Aclaraciones y agradecimientos}

Estudio financiado por el Ministerio de Economía y Competitividad del Gobierno de España en el marco del proyecto EDU2016-77576-P.

\section{Sobre los autores}

Diego Martín-Alonso es doctor de la Universidad de Málaga, España. Sus líneas de investigación se centran en el estudio de la experiencia educativa, los saberes docentes y la formación inicial del profesorado. 
Nieves Blanco-García es catedrática en el Departamento de Didáctica y Organización Escolar de la Universidad de Málaga, España. Especializada en currículum y formación del profesorado, con énfasis en los saberes docentes y su implicación en la formación inicial del profesorado.

J. Eduardo Sierra-Nieto es doctor de la Universidad de Málaga, España. Actualmente trabaja como profesor ayudante doctor en el Departamento de Teoría de la Educación. Sus líneas de investigación son: experiencia escolar, subjetividad y saberes docentes.

\section{Referencias}

Aoki, T. T. (2012). Curriculum in a New Key: The Collected Works of Ted T. Aoki. (W. Pinar y R. L. Irwin, Eds.). New York: Routledge.

Ayala, R. (2011). La esperanza pedagógica: una mirada fresca y profunda a la experiencia educativa desde el enfoque de Van Manen. Revista Española de Pedagogía, 248, 119-144. Recuperado de https://dialnet.unirioja.es/servlet/ articulo?codigo $=3365094$

Ayala, R. (2018). La relación pedagógica: en las fuentes de la experiencia educativa con Van Manen. Revista Complutense de Educación, 29(1), 27-41. doi: 10.5209/RCED.51925

Biesta, G. (2017). El bello riesgo de educar. Madrid: SM.

Blanco, N. (2011). Sostener la libertad: encontrar y cuidar un "cuarto propio". Revista Interuniversitaria de Formación del Profesorado, 70(25,1), 77-92. Recuperado de https://www.redalyc.org/articulo.oa?id=27419147005

Bustamante-Zamudio, G. (2012). Pedagogía de Kant: ¿una filosofía de la educación?. Magis, Revista Internacional de Investigación en Educación, 5(10). Recuperado de https://revistas.javeriana.edu.co/index.php/MAGIS/article/ view/4171

Cima, R. (2012). Pedagogía cultural para una educación hacia el encuentro. RUEDES, 3, 1-17. Recuperado de https://bdigital.uncu.edu.ar/objetos_digita les/4339/cimmaruedes3.pdf

Clandinin, D. J. (2013). Engaging in narrative inquiry. Walnut Creek, CA: Left Coast.

Clandinin, D. J. \& Connelly, F. M. (1998). Stories to live by: Narrative understandings of school reform. Curriculum Inquiry, 28(2), 149-164. doi: 10.1111/03 62-6784.00082

Contreras, J. (2002). Educar la mirada ... y el oído: percibir la singularidad y también las posibilidades. Cuadernos de Pedagogía, 311, 61-65.

Contreras, J. (2010). Pedagogías de la experiencia y la experiencia de la pedagogía. En J. Contreras \& N. Pérez de Lara (Eds.), Investigar la experiencia educativa (pp. 241-271). Madrid: Morata.

Contreras, J. (Ed.). (2016). Tensiones fructíferas: explorando el saber pedagógico en la formación del profesorado: una mirada desde la experiencia. BarceIona: Octaedro.

Gimeno, J. (1988). El curriculum: una reflexión sobre la práctica. Madrid: Morata.

Goldstein, L. S. (1998). Taking caring seriously: The ethic of care in classroom life. Ponencia presentada en Annual Meeting of the American Educational 
Research Association, San Diego. Recuperado de http://eric.ed.gov/?id= ED419801

Huber, J., Murphy, M. S. \& Clandinin, D. J. (2011). Places of Curriculum Making: Narrative Inquiries into Children's Lives in Motion. Bingley: Emerald.

Jordán, J. A. (2011). Disposiciones esenciales de los profesores en las relaciones con sus alumnos desde una perspectiva ética-pedagógica. Educación XX1, 14(1), 59-87. doi: 10.5944/educxx1.14.1.263

López, A. (2006). Hacerse mediación viva. En A. M. Piussi \& A. Mañeru (Eds.), Educación, nombre común femenino (pp. 134-157). Barcelona: Octaedro.

Martín-Alonso, D., Blanco, N. \& Sierra, J. E. (2019). Comprensión pedagógica y construcción de la relación educativa. Una indagación narrativa. Teoría de la Educación. Revista Interuniversitaria, 31(1), 103-122. Recuperado de https:// revistas.usal.es/index.php/1130-3743/article/view/teri.19442

Molina, M. D., Blanco, N. \& Arbiol, C. (2016). Dejarse tocar para que algo nos suceda. En J. Contreras, Tensiones fructíferas: explorando el saber pedagógico en la formación del profesorado. Una mirada desde la experiencia (pp. 111-150). Barcelona: Octaedro.

Montoya, M. M. (Ed.). (2004). Recetas de relación: educar teniendo en cuenta a la madre. Madrid: Horas y Horas.

Montoya, M. M. (2006). Ser en confianza. En A. M. Piussi \& A. Mañeru (Eds.), Educación, nombre común femenino (pp. 85-113). Barcelona: Octaedro.

Noddings, N. (2005). Identifying and responding to needs in education. Cambridge Journal of Education, 35(2), 147-159. doi: 10.1080/03057640500 146757

Piussi, A. M. \& Mañeru, A. (Eds.). (2006). Educación, nombre común femenino. Barcelona: Octaedro.

Rivera, M. M. (2012). El amor es el signo: educar como educan las madres. Madrid: Sabina.

Sierra, J. E. \& Blanco, N. (2017). El aprendizaje de la escucha en la investigación educativa. Qualitative Research in Education, 6(3), 303-326. doi: 10.17583/ qre.2017.2783

Stenhouse, L. (1987). La investigación como base de la enseñanza. Madrid: Morata.

Van Manen, M. (1998). El tacto en la enseñanza: el significado de la sensibilidad pedagógica. Barcelona: Paidós.

Van Manen, M. (2003). Investigación educativa y experiencia vivida: ciencia humana para una pedagogía de la acción y la sensibilidad. Barcelona: Idea.

Van Manen, M. (2015). Pedagogical Tact: Knowing what to Do when you don't Know what to Do. Walnut Creek, CA: Left Coast.

Wilson, C. (2014). Towards a thinking and practice of sexual difference: Putting the practice of relationship at the centre. Journal of Philosophy of Education, 48(2), 202-215. doi: 10.1111/1467-9752.12067

Zambrano, M. (2007). Filosofía y educación: manuscritos (A. Casado \& J. Sánchez-Gey, Eds.). Málaga: Ágora. 